\section{The Handbook of Pluralist Economics Education}

Reardon, J. (ed.), Advances in Heterodox Economics, Routledge Press: London, UK and New York, 2009. 304 pp., ISBN 978-0-415-77762-9 (hb). £75.00 (hb)

Undergraduate education has come under increasing criticism for not providing key skills that graduates need to be productive members of society. For example, the Association of American Colleges and Universities (AAC\&U) argues that a liberal education should involve more breadth and less depth than it currently does. They see a liberal education as one that instils in students a strong sense of values, ethics, and civic engagement ${ }^{1}$. Accordingly, they see a liberal education as a way of learning rather than as learning specific content.

The pluralist economics education movement provides an avenue for incorporating goals of liberal education with those of the economics major, complementing characteristics often associated with the goal of teaching students to 'think like economists' with explicit recognition that knowledge is constructed. Economic educators supportive of pluralism suggest that this can be achieved, in part, by providing a context for understanding current knowledge (via history of economic thought), discussing competing paradigms, and broadening traditional boundaries of economics.

The Handbook of Pluralist Economics Education contributes to the growing conversation among pluralists dedicated to reforming undergraduate economics education by seeking to 'provide practical suggestions... to implement pluralism', 'increase pedagogical influence of pluralists', increase critical thinking in economics' and 'increase student interest in economics' (p.7). Its 14 original essays begin with a series of arguments in favour of promoting pluralism, followed by thematic groupings dedicated to the principles course, core courses, and more advanced or elective courses.

Despite an introductory statement suggesting the case for pluralism has already been made, four essays are dedicated to this argument. For those less familiar with such arguments, these chapters provide key insights regarding the importance of history of thought and methodology and provide perspectives from often neglected voices, those of graduate and undergraduate students. Nonetheless their inclusion conflicts with the main goal of the volume, taking precious space away from its ability to 'offer suggestions for instructors to incorporate pluralist methods into pedagogy'. (p.6)
Subsequent chapters focusing on various courses and fields within the economic major demonstrate that indeed 'pluralism is multifaceted' ( $p .556)$. These chapters provide a range of approaches for pluralising economics education which include reframing a specific course, providing quantitative challenges, addressing the student audience and educating the instructor. Because the wide range of approaches provides insight for novices and experts, these chapters should appeal to an equally wide-ranging audience.

Reframing a specific course first requires acknowledgement of existing practices, and chapters by Nelson (principles) and Champlin and Wiens-Tuers (labour) use this perspective to ground their discussion. Nelson describes three approaches typically undertaken to broaden the principles course beyond the dominant orthodox tradition - single alternative, competing paradigms, and bigger questions and bigger toolbox - before arguing that the latter is 'more congruent with a pluralist, rather than paradigmatic, approach to economic research and teaching' (p.60) because it 'adopts a more tolerant and synthetic, rather than adversarial, approach to teaching models and methods' (p.65). She supports this approach with discussions on both content and pedagogical practice as well as by providing a rich annotated bibliography of supporting resources. A more topical approach is taken by Champlin and Wiens-Tuers who review key topics in a traditional labour economics course (defining labour, wage determination, wage differentials, labour market structure), and provide examples of how presentations might be broadened to incorporate pluralistic content.

The heavily quantitative nature of economics often leads students to take mathematical gymnastics and their resulting conclusions at face value. Keen (in both his chapters on microeconomic theory and mathematics), however, argues that 'mathematics (and computing) can and should play a role in the development of political economy' (p. 151). For example, Keen's approach to microeconomics begins by employing mathematics to demonstrate that key aspects of traditiona microeconomic theory are false, setting the stage for 'convincing students that a different approach should be considered' (p. 120).

Another approach to pluralising course content is to provide materials that are readily accessible to students as well as faculty. Although perhaps not intended as such, Madi and Goncalves' International Economics chapter could be assigned to students at the start of the semester to provide an alternative context for more traditional materials prevalent in textbooks. The inclusion of informative inserts describing classical texts, key definitions, important concepts and website references provide students with an historical lens by which to view current events. In-class activities complement the content although some may be beyond the reach of students without additional guidance.

Educating the instructor is a critical first step in fields which are undergoing a pluralist revolution (sustainability economics) or in newly emerging fields (green economics). 
Soderbaum describes key arguments demonstrating that traditional economics is inconsistent with sustainable economics and demonstrates his case using a comparison of orthodox and institutional economics. He argues that'meeting the challenge of sustainable development requires new thinking' and that providing students with a range of perspectives on environmental issues sets the stage for them to'make their own interpretations and judgments' (p.195). Kennet argues that'green economics is by its nature multi-, inter- and trans-disciplinary' (p.256) and that as such it represents a new paradigm, ripe for realisation of pluralistic ideals. However, she suggests that the main message of green economics has been 'usurped and distorted' (p.258) and offers her interpretation of key core principles before addressing pedagogic implications.

While the wide range of methods used to offer insights into a pluralistic economics education may appeal to many audiences, most chapters fall short of discussing pedagogic practices. These chapters instead focus primarily on content, a trap into which many who argue for economic education reform fall. As argued elsewhere, reforms should not neglect pedagogic practice. (McGoldrick and Peterson, 2009; McGoldrick, 2009) Additionally, at times authors are so committed to their approach (one which often focuses on disparaging orthodoxy) that they may undermine the goal of engaging readers,'no matter what their ideology' (p.6).

These criticisms notwithstanding, this collection of essays provides a much needed contribution to the pluralist economics education discussion. The organisational structure makes the volume accessible to those who are better versed in this approach to economics education as well as those who are novices. The arguments presented speak to both educators and students, expanding the realm of the conversation beyond its traditional participants. In short, everyone who is serious about undergraduate economics education should put this volume on their 'must-read' list.

\section{References}

McGoldrick, KimMarie (2009) 'Pluralism and Economic Education, Promoting Change: Past, Present, and Future', in Economic Pluralism, Robert Garnett, Erik Olsen and Martha Starr (eds), Routledge: pp. 221-225.

McGoldrick, KimMarie and Janice Peterson (2009) 'Pluralism and Economic Education: A Learning Theory Approach', International Review of Economics Education.

\section{Endnote}

1 For a detailed description of each of these skills, see Appendix A, AAC\&U (2007).

\section{Reviewed by:}

KimMarie McGoldrick

Robins School of Business

28 Westhamton Way, Richmond, VA 23060

United States

\section{Teaching Pluralism in Economics}

By Groenewegen, John (ed.), Edward Elgar Publishing: Cheltenham, 2007. ISBN $9781845423056(h b), f 59.95(h b)$

Teaching Pluralism in Economics is an ambitious collection of 11 essays addressing the potential for more pluralistic and interdisciplinary approaches to economic education. The essays range from those addressing pluralism and interdisciplinarity at a theoretical level to case studies that apply these principles in particular courses and institutions. The first essay, by the volume's editor John Groenewegen, introduces and defines some of the key concepts and goals of the volume. He states that the volume is about 'different schools within the discipline of economics' (theoretical pluralism) and 'the relation of economics with other disciplines' (interdisciplinarity), and seeks to address the 'implications of pluralism and interdisciplinarity' for teaching economics (p.1). He believes the fundamental challenge is to present alternative theories to students in ways that are not confusing but allow for a better understanding of the 'possibilities and limitations of different schools in economics' and how to proceed when 'the boundaries of the economics discipline have been reached and a more interdisciplinary approach is needed' (p.14).To meet this challenge, the volume offers 'insights into the question of the content of such a revised curriculum and into the process of how to get there' (p.15).

Reflecting the fact that the literature on 'pluralism in economics' is itself a pluralistic one, the 10 contributed essays offer diverse views on what a more pluralistic/interdisciplinary economic education should look like and how it should be achieved. Evaluating the contributions of the volume from the perspective of economic education, several broad themes emerge:

- In an increasingly complex and changing world, a more pluralistic/interdisciplinary approach to economic education is necessary to prepare properly and inform policy-makers.

- History, real-world economic processes and problems, and student engagement are key components of a more pluralistic/interdisciplinary approach to economic education. 